\title{
Chemical fibrosis: the model of silica
}

\author{
MARGARET TURNER-WARWICK, PETER COLE, HANS WEILL, \\ R. N. JONES, AND MORTON ZISKIND
}

From the Department of Medicine, Cardiothoracic Institute, London, and the Pulmonary Diseases Section, Tulane University, New Orleans, USA

The interesting feature of silica in the context of this symposium is its dramatic and characteristic influence on the development of fibrosis in the lung (Fig. 1). A vast number of agents cause an organizing inflammatory response in the lung, and the balance between resolution on the one hand and organization (or, more properly, disorganization) with fibrosis on the other depends on many factors. The fibrosis in most of these cases tends to be widespread, affecting alveolar walls and to a varying extent the respiratory bronchioles.
The effects of silica on the lung stand in sharp contrast to those of many other causes of pulmonary fibrosis. It is important to recognize that a clear distinction has to be made between the histological features resulting from pure quartz exposure (as found in sand blasters, the subject of the present report) and those resulting from mixed dust exposure in coal miners (exposed to rock dust of variable silica content), mixed dust exposure with inert material (such as ferrous oxide), and diatomite pneumoconiosis from calcinated diatomaceous earth.

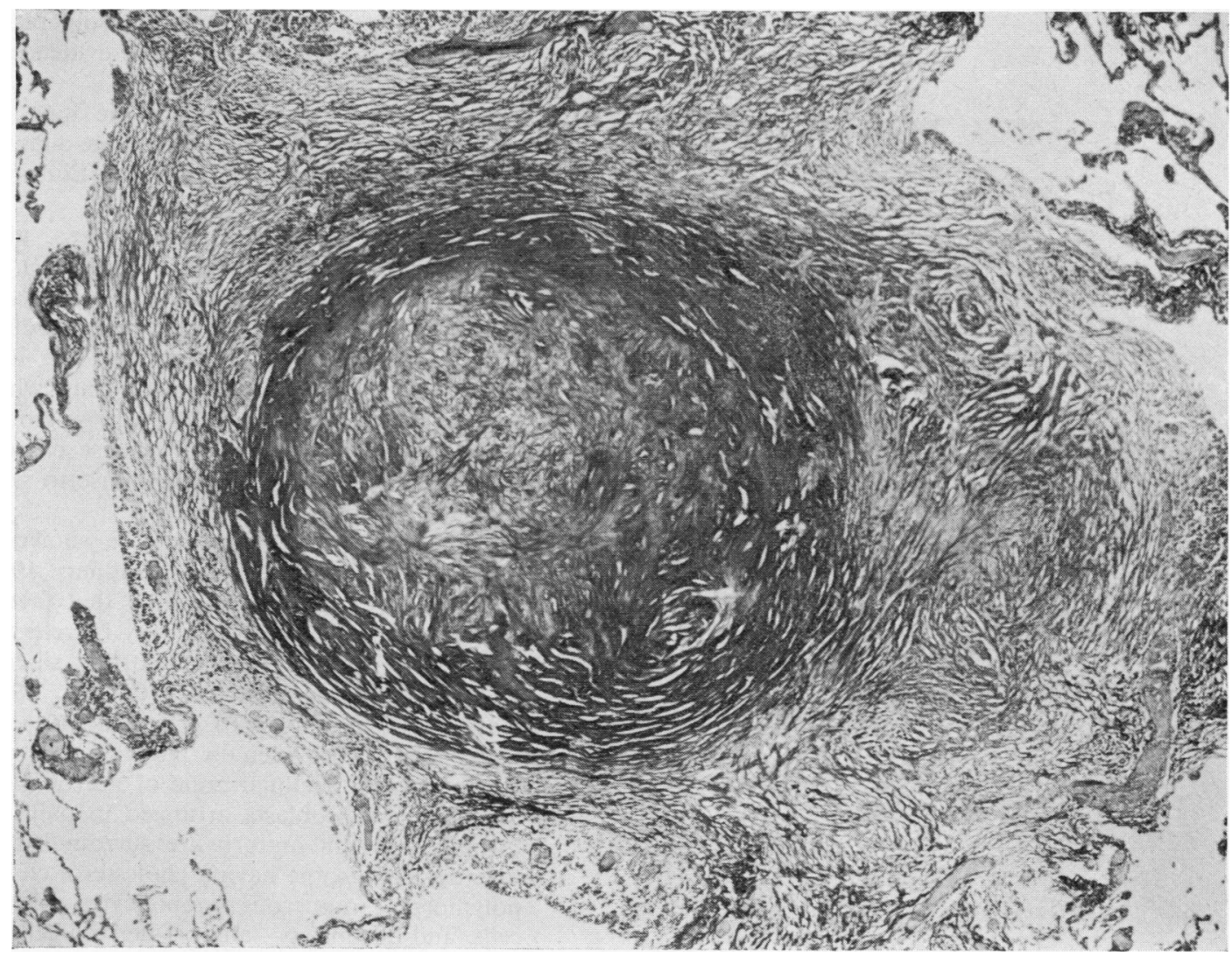

FIG. 1 Lung fibrosis due to silica. $\times 235$ 
Long-standing exposure to large amounts of relatively pure silica causes a highly characteristic fibrotic nodulation of the lung, with whorls of exuberant fibrosis leaving the intervening lung relatively normal. The large dimensions of the fibrotic lesions are reflected in a characteristic radiographic pattern (Fig. 2). Polarized light demonstrates the density of silica particles embedded within the nodules of fibrosis and in adjacent lymph nodes.

Two processes complicate this primary nodular pattern of response-one is very uncommon, the other common. The first, seen in experimental animals and occasionally in man, is an acute alveolar proteinosis. The features of the histological amorphous mass as seen by light microscopy are shown by the electron microscope as extensive macrophage disintegration. This non-fibrotic process is outside the context of the present paper. The second complication is the conglomeration of fibrotic nodules occurring particularly in the upper lobes of the lung. These appearances are to be distinguished from upper lobe contraction and cavitation, which were often associated in the past with tuberculosis.

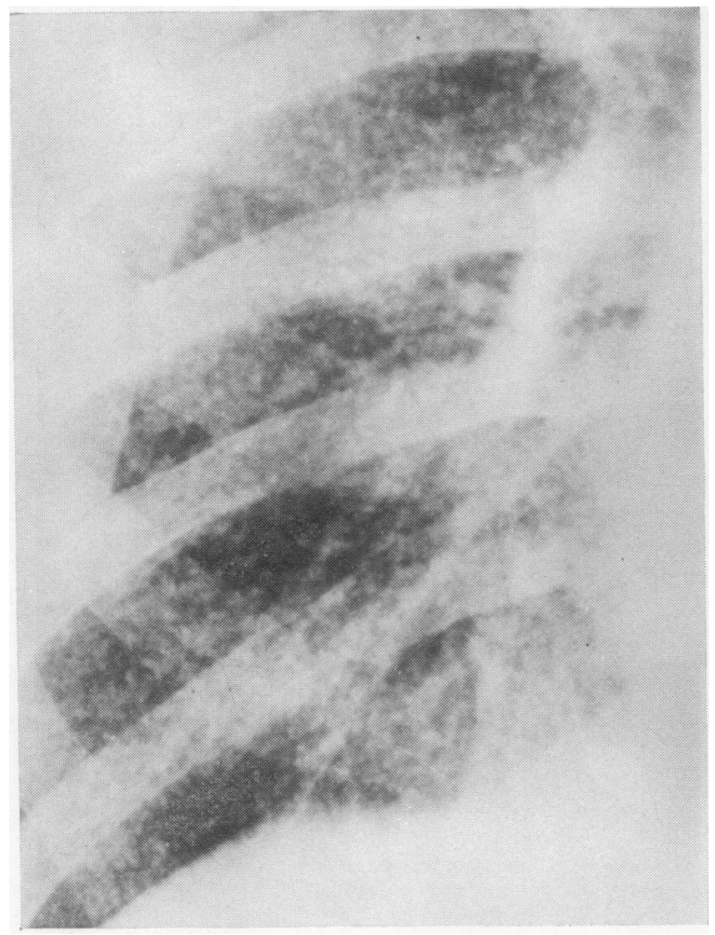

FIG. 2 Characteristic radiographic pattern in pulmonary silicosis

\section{Dose dependence}

Various questions of biological importance are posed.

(1) To what extent is the development of the whorled fibrotic nodules simply dose-dependent, affecting all individuals exposed to similar amounts of dust?

(2) To what extent does the amount of fibrosis depend on the host propensity to respond? This questions the capacity of macrophages to respond, handle, and eliminate the dust as well as questioning other factors determining fibroblastic response.

(3) If the primary nodulation can be shown to be largely or wholly dose-dependent does the tendency to form conglomerate lesions depend more on host factors? The natural analogy here is the development of Caplan's nodules in coal miners who have rheumatoid arthritis.

(4) When host factors can be demonstrated are they contributing to the development of lesions or are they the consequences of them?

The evidence for other than dose factors can be summarized as follows.

(1) Fibrotic nodules in silicosis show proliferation of excess host collagen with little evidence of residual dust.

(2) The longer quartz remains in the lung the greater the fibrosis and the smaller the quantity? of dust required to stimulate fibrosis (Einbrodt, 1965).

(3) The size of nodules may progress after removal from exposure (Heppleston, 1962).

(4) The development of accelerated silicosis is seen in some instances with ill-defined nodular fibrosis extending into the surrounding lung and containing numerous plasma cells, which in turn contain demonstrable gamma-globlin (Ceppellini and Pernis, 1958). These changes show the variability of host response to silica dust.

(5) Experimental tuberculosis can be shown to have an enhancing effect (Gardner, 1929; Policard et al., 1967), indicating that factors other than the dose of silica may be relevant.

(6) The development of 'rheumatoid' silicotic nodules has been described (Colinet, 1953; Hayes and Posner, 1960). These nodules are larger than those seen in pure silicosis and have a central acellular zone of necrosis surrounded by fibroblasts arranged in pallisade formation which in turn are surrounded by macrophages (some having cholesterol clefts), polymorphs, numerous lymphocytes, plasma cells, and fibroblasts - all host-derived cells.

(7) Several groups of workers have reported the association of 'connective tissue disease', 
especially scleroderma, in silica workers (Bramwell, 1914; Erasmus, 1960; Rodnan et al., 1967). Jones et al. (1976) found four cases of scleroderma among 55 silica workers and two cases with rheumatoid arthritis. They also described a syndrome like systemic lupus erythematosus in occasional cases.

(8) Previous reports of tissue antibodies, especially rheumatoid factor and antinuclear antibody, in various types of silica workers (Kang et al., 1973; Lippman et al., 1973; Ceppellini and Pernis, 1958) have now been confirmed (Jones et al., 1976).

\section{Study of sand blasters}

The study reported here was undertaken jointly with Professor Hans Weill and his colleagues in New Orleans, and concerns 39 sand blasters exposed to pure quartz. Their mean age was 46 years (range 28 to 57 ) and the duration of exposure varied from one to 32 years.

\section{IMMUNOLOGICAL STUDIES}

The results of immunological studies are summarized in Table I. Antinuclear antibody (demonstrated by a standard double-layer immunofluorescent test using serum dilution of 1 in 10) was found in 17 out of the $39(44 \%)$. Antibodies to single-stranded DNA were demonstrated by double Ouchterlony diffusion (and confirmed by counter-current electrophoresis) in 9 out of $22(41 \%)$ silicotic patients. The complement-fixing potential of antinuclear antibody was sought by the immunofluorescent method described by Lachmann et al. (1962) but was found in only $14 \%$ of our series. Nucleoprotein antibody was sought using nucleoprotein smears and an immunofluorescent technique, but was found in only one subject.

\section{CLINICAL CORRELATES}

There was no apparent correlation between the presence of antinuclear antibodies with age, race, smoking habits, or length of exposure to silica (Table II).

Table I Properties of ANA antibodies in silicosis

\begin{tabular}{lllll}
\hline & $\begin{array}{l}\text { No. } \\
\text { tested }\end{array}$ & & \multicolumn{2}{l}{ Positive } \\
\cline { 4 - 5 } \cline { 4 - 5 } & & & No. & $\%$ \\
\cline { 1 - 2 } Prevalence* & 39 & & 17 & 44 \\
SS-DNA precipitation & 22 & & 9 & 41 \\
Complement fixing & 22 & & 3 & 14 \\
Nucleoprotein antibody & 22 & & 1 & 5 \\
\hline
\end{tabular}

*ANA by immunofluorescence serum diluted 1:10
Table II Characteristics of ANA-positive and ANA-negative populations

\begin{tabular}{|c|c|c|}
\hline $\begin{array}{l}\text { Total series } \\
(n=39)\end{array}$ & $\begin{array}{l}\text { ANA-positive } \\
(n=17)\end{array}$ & $\begin{array}{l}\text { ANA-negative } \\
(n=22)\end{array}$ \\
\hline \multicolumn{3}{|l|}{ Age (years) } \\
\hline $\begin{array}{l}\text { mean } \\
\text { range }\end{array}$ & $\begin{array}{l}46 \cdot 6 \\
28-67\end{array}$ & $\begin{array}{l}46 \cdot 0 \\
28-57\end{array}$ \\
\hline \multicolumn{3}{|l|}{ Race (no.) } \\
\hline $\begin{array}{l}\text { Negro } \\
\text { White }\end{array}$ & $\begin{array}{l}8(47 \%) \\
9(53 \%)\end{array}$ & $\begin{array}{l}10(45 \%) \\
12(55 \%)\end{array}$ \\
\hline Smoking (years) & $30 \cdot 1$ & $28 \cdot 2$ \\
\hline \multicolumn{3}{|c|}{ Exposure to silica (years) } \\
\hline $\begin{array}{l}\text { mean } \\
\text { range }\end{array}$ & $\begin{array}{c}11 \cdot 4 \\
5-23\end{array}$ & $\begin{array}{c}13 \cdot 2 \\
1-32\end{array}$ \\
\hline
\end{tabular}

Table III Relationship between extent of radiographic lesions and incidence of $A N A$ in silicosis

\begin{tabular}{|c|c|c|c|c|c|c|c|}
\hline \multicolumn{2}{|c|}{ Simple lesions } & \multicolumn{6}{|c|}{ Conglomerate lesions } \\
\hline \multirow[t]{2}{*}{ No. } & \multirow[t]{2}{*}{$\%$} & \multicolumn{2}{|l|}{$A$} & \multicolumn{2}{|l|}{$\boldsymbol{B}$} & \multicolumn{2}{|l|}{$C$} \\
\hline & & No. & $\%$ & No. & $\%$ & No. & $\%$ \\
\hline $5 / 18$ & 28 & $\begin{array}{l}2 / 7 \\
\chi^{2} \\
\end{array}$ & $\begin{array}{l}29 \\
\text { P C }\end{array}$ & $\begin{array}{l}6 / 9 \\
5\end{array}$ & 66 & $4 / 5$ & (D) \\
\hline
\end{tabular}

Table IV Clinical assessment of lung functiog : initial series

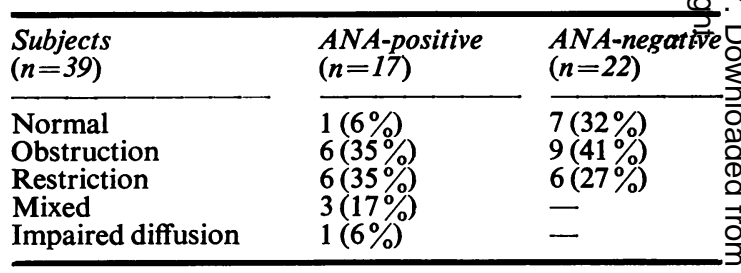

Table V Clinical assessment of lung function: follow-up study after two years

\begin{tabular}{lll}
$\begin{array}{l}\text { Subjects } \\
(n=29)\end{array}$ & $\begin{array}{l}\text { ANA-positive } \\
(n=14)\end{array}$ & $\begin{array}{l}\text { ANA-negative } \\
(n=15)\end{array}$ \\
& $2(14 \%)$ & $6(40 \%)$ \\
Normal & $4(29 \%)$ & $4(27 \%)$ \\
Obstruction & $4(29 \%)$ & $3(20 \%)$ \\
Restriction & $3(21 \%)$ & $2(13 \%)$ \\
Mixed & $1(7 \%)$ & - \\
Impaired diffusion & 10 \\
\hline
\end{tabular}

\section{RADIOLOGY}

The extent of conglomerate lesions, however, was $\omega$ related to antinuclear antibody (Table III) ( $\chi$ ) trend $0 \cdot 05$ ).

\section{PHYSIOLOGY}

The physiological abnormality was similar in the antinuclear antibody-positive and negative cases, 
but significantly more antinuclear antibody-negative patients had completely normal lung function (Table IV). This finding was confirmed in the follow-up study where $40 \%$ of 15 patients with no antinuclear antibody had normal lung function compared with only $14 \%$ of these having detectable antinuclear antibody (Table V).

\section{Discussion}

The development of antinuclear antibody in this group of sand blasters with silicosis is greatly increased above that for normal men of comparable age. The titre and prevalence is greater than in asbestos workers (Turner-Warwick and Parkes, 1970) or in one group of coal miners (Soutar et al., 1974). A comparable prevalence, however, has been described in coal miners exposed to a large amount of quartz (Lippmann et al., 1973).

The correlations reported here seem to relate antinuclear antibody to progressive increase in size of large lesions. Ceppellini and Pernis (1958) suggested many years ago that the development of such lesions might depend on additional unspecified host factors, perhaps immunologically determined, and it is tempting from the present study to invoke the development of antibodies to nuclear constituents in particular. In a further follow-up study of this group of workers a few of them who were initially antinuclear antibody negative have developed antibody. Thus progression of silicosis does not depend in all cases on long-standing preexisting antinuclear antibody.

Whether antinuclear antibody results from the formation of conglomerate lesions or accelerates their formation still remains unresolved. The precise interrelationship could now be explored in animal models. If an accelerating role for antinuclear antibody could be defined it would, firstly, suggest the possibility of detecting accelerating cases and, secondly, the possible role of similar tissue antibodies in other inflammatory diseases.

\section{Conclusions}

(1) Antinuclear antibody has been found in 17 out of $39(44 \%)$ sand blasters with silicosis. (2) Preliminary evidence suggests a relationship of the antinuclear antibodies to the size of conglomerate lesions and deterioration in lung function. (3) Advancing silicotics do not seem to be those with longstanding pre-existing antinuclear antibodies. (4) The exact cause and effect of the relationship between progression and development of antinuclear antibody is not clear. The model of accelerated silicosis developing within a reasonably short follow-up period may be useful to establish the sequence of this relationship. This information may then be applicable to fibrosing disorders of the lung from other causes. 